\title{
PERAN ASRAMA MAHASISWA KALIMANTAN TIMUR (AMKT) RUHUI RAHAYU DALAM PROSES KOMUNIKASI ANTAR BUDAYA DI BACIRO, GONDOKUSUMAN, YOGYAKARTA
}

\author{
Winarni Karim dan Puji Lestari \\ Jurusan Pendidikan Sosiologi, Fakultas IImu Sosial, Universitas Negeri Yogyakarta \\ Email : winarnikariim@gmail.com
}

\begin{abstract}
Abstrak
Penelitian ini mendeskripsikan peran, proses komunikasi antarbudaya, faktor pendorong dan penghambat, serta dampak peran AMKT Ruhui Rahayu dalam proses komunikasi antarbudaya di Baciro, Gondokusuman,Yogyakarta. Penelitian ini menggunakan metode kualitatif. Pengambilan sampel menggunakan purposive sampling dengan informan berjumlah 12 orang. Teknik analisis data menggunakan teknik analisis Miles dan Huberman yang terdiri dari pengumpulan data, reduksi data, penyajian data dan penarikan kesimpulan. Hasil penelitian menunjukkan peran AMKT Ruhui Rahayu dalam proses komunikasi antarbudaya melalui peraturan asrama dan kegiatan yang melibatkan anggota AMKT Ruhui Rahayu dan warga. Proses komunikasi antarbudaya berlangsung secara langsung melalui kegiatan dan tidak langsung menggunakan undangan sebagai media. Faktor pendorong intrinsik peran AKMT Ruhui Rahayu dalam komunikasi antarbudaya yaitu kesadaran anggota AMKT Ruhui Rahayu dan ekstrinsik yaitu keterbukaan dan penerimaan baik dari warga. Sedangkan faktor penghambat adalah waktu. Anggota AMKT Ruhui Rahayu dan warga bisa berkomunikasi lebih intensif melalui berbagai acara atau kegiatan. Dampak peran AMKT Ruhui Rahayu merupakan dampak positif yaitu mempermudah pengenalan kebudayaan dan saling mendukung dalam berbagai kegiatan.

Kata Kunci: Peran, Komunikasi Antarbudaya, Asrama Mahasiswa Daerah.
\end{abstract}

\section{Abstract}

This research described the role, the intercultural communication process, the driving and obstacle factors, and the impact of Asrama Mahasiswa Kalimantan Timur (AMKT) Ruhui Rahayu on the intercultural comunication process in Baciro, Gondokusuman, Yogyakarta. This research used qualitative method. Sampling was done by 12 person. The analysis technique use in this research was Miles and Huberman's analysis technique that consisted of data collection, data reduction and making conclusion. The results of the study showed the role of AMKT Ruhui Rahayu in the intercultural communication process through dormitory regulations and activities involving AMKT members Ruhui Rahayu and residents. The intercultural communication process is carried out directly through activities and indirectly, using invitations as media. The intrinsic driving factor of the role of AKMT Ruhui Rahayu in intercultural communication is the awareness of AMKT members Ruhui Rahayu and extrinsic namely the openness and good acceptance of citizens. While the obstacle factor is time. AMKT Ruhui Rahayu member and residents can communicate more intensively through various events/ activities. The impact of the rule of AMKT Ruhui Rahayu is a positive impact that make it easier the introduction of culture and supports each other in various activities. Keywords: Role, Intercultural Communication, Regional Student Dormitory 


\section{Pendahuluan}

Yogyakarta merupakan provinsi dengan berbagai keistimewaan. Salah satu bentuk keisimewaannya adalah dikenal sebagai kota pelajar. Hal tersebut menjadi daya tarik bagi calon mahasiswa dari berbagai wilayah Indonesia. Sebagaimana data pada kompas 9 April 2013 bahwa, pada tahun 2013 terdapat 310.860 mahasiswa. Sekitar 244.739 atau $78,7 \%$ merupakan mahasiswa perantau yang berasal dari luar daerah (Susanto:2016). Tingginya jumlah mahasiswa perantau yang ada di Yogyakarta, menjadi salah satu hal yang melatarbelakangi pemerintah daerah dari beberapa wilayah di Indonesia untuk memutuskan mendirikan asrama daerah di Yogyakarta.

Adapun tujuan pendirian asrama adalah untuk memberikan fasilitas kepada putra daerah yang sedang melanjutkan pendidikan. Namun, berkembangnya jumlah asrama menyebabkan permasalahan tersendiri dan juga potensi konflik. Hal tersebut karena perbedaan budaya. Adapun bentuk permasalahannya terkait pandangan bahwa asrama cenderung tertutup. Disamping itu bentuk konflik yang pernah terjadi sebagaimana yang termuat dalam (Purwaningsih, 2014:2) bahwa pada tahun 2013 terdapat konflik antara mahasiswa asrama dengan warga di daerah Babarsari, konflik tersebut dipicu oleh kebiasaan anggota asrama yang dianggap mengganggu masyarakat setempat.

Berdasarkan pada permasalahan dan konflik yang melibatkan anggota asrama mahasiswa daerah sebagaimana yang telah dijelaskan sebelumnya. Keberadaan asrama daerah pada lingkungan yang memiliki kebudayaan berbeda merupakan salah satu penyebab permasalahan tersebut. Untuk itu memperkuat berbagai peran asrama daerah sangat diperlukan. Keberadaan asrama daerah pada lingkungan yang memiliki kebudayaan berbeda merupakan salah satu penyebab permasalahan tersebut. Untuk itu memperkuat berbagai peran asrama terutama dalam membangun komunikasi dengan masyarakat sekitar lingkungan asrama sangat diperlukan. Hal tersebut dapat menjadi solusi untuk mengatasi permasalahan dan konflik yang ada. Asrama Mahasiswa Kalimantan Timur (AMKT) Ruhui Rahayu merupakan salah satu asrama daerah yang memiliki kegiatan aktif bersama masyarakat setempat. Untuk itu peneliti mengkaji lebih dalam terkait "Peran Asrama Mahasiswa Kalimantan Timur (AMKT) Ruhui Rahayu dalam Proses Komunikasi Antarbudaya di Baciro, Gondokusuman, Yogyakarta”.

\section{Metode}

Penelitian ini menggunakan metode penelitian kualitatif dengan pendekatan deskriptif analisis. Teknik pengumpulan data menggunakan observasi, wawancara dan dokumentasi. Pemilihan informan dalam penelitian ini menggunakan teknik purposive sampling dengan kriteria informan yaitu pengurus dan anggota 
Asrama Mahasiswa Kalimantan Timur (AMKT) Ruhui Rahayu, Alumni AMKT Ruhui Rahayu ( pengurus dan non pengurus). Sedangkan kriteria warga RT.33 RW.09 Baciro, Yogyakarta adalah warga yang tinggal di sekitar AMKT Ruhui Rahayu. Adapun yang menjadi informan dalam penelitian ini adalah pengurus AMKT Ruhui Rahayu, anggota AMKT Ruhui Rahayu, Alumni AMKT Ruhui Rahayu, Ketua RT dan RW dan warga sekitar lingkungan asrama.

\section{Hasil dan Pembahasan}

1. Peran AMKT Ruhui Rahayu dalam Proses Komunikasi Antarbudaya.

Asrama Mahasiswa Kalimantan Timur (AMKT) Ruhui Rahayu sebagai tempat tinggal sekaligus tempat bersosialisasi mewajibkan semua anggotanya untuk bisa membangun komunikasi yang baik dengan warga. Peran AMKT Ruhui Rahayu dalam proses komunikasi dengan warga dijalankan melalui berbagai peraturan dan kegiatan bersama warga. Peraturan merupakan salah satu unsur pokok dalam pelaksanaan peran. Adapun bentuk peraturan AMKT Ruhui Rahayu adalah penerapan $3 \mathrm{~S}$ (senyum, sapa dan salam). Peraturan $3 \mathrm{~S}$ menjadi peraturan pokok bagi seluruh AMKT Ruhui Rahayu, mulai dari lingkup internal yaitu sesama anggota asrama dibiasakan untuk senyum, sapa dan salam. Penerapan peraturan $3 S$ diawali dari sesama anggota asrama kemudian diterapkan dalam berkomunikasi dengan warga.

Penerapan peraturan $3 S$ bagi seluruh anggota asrama, adalah bagian dari pelaksanaan komunikasi antarbudaya dengan warga yang dimulai dengan saling bertegur sapa. Penerapan 3S bermanfaat dalam menjaga proses komunikasi khusunya sesama anggota AMKT Ruhui Rahayu dan bermanfaat untuk membangun komunikasi dengan warga.

Penerapan peraturan asrama mengarahkan anggotanya untuk beradaptasi, berkomunikasi dan berperan aktif sebagai bagian dari masyarakat setempat. Hal ini sejalan dengan pendapat Levison (2006) bahwa peran berkaitan dengan aturan yang mengarahkan seseorang dalam kehidupan bermasyarakat. Peran AMKT Ruhui Rahayu dalam proses komunikasi antarbudaya juga diterapkan melalui aturan yang membiasakan anggota asrama untuk tertib dan mengikuti berbagai peraturan dilingkungan warga RT 33/ RW 09 Baciro.

Melalui pembiasaan dilingkungan asrama untuk selalu tertib dengan berbagai peraturan bermanfaat menumbuhkan kesadaran anggota AMKT Ruhui Rahayu terkait pentingnya mengikuti berbagai peraturan di lingkungan masyarakat. Ketertiban terhadap peraturan dimasyarakat berdampak pada proses komunikasi dengan masyarakat. Disamping itu peran AMKT Ruhui Rahayu dilaksanakan melalui beberapa peraturan sebagai berikut:

a. Senam bersama warga RW 09 Baciro 
Senam dilaksanakan setiap hari Minggu pukul 06.00 - selesai yang bertempat di lapangan yang berada di jalan Kantil RT 33/ RW 09 Baciro. Senam merupakan salah satu kegiatan rutin asrama bersama warga sekitar asrama. Senam merupakan kegiatan warga yang juga dimasukkan dalam kegiatan atau program kerja asrama yang dikelola oleh divisi keolahragaan dan kebudayaan. Saat senam berlangsung, warga dan anggota asrama saling membaur dalam barisan senam. Setelah senam selesai sambil beristirahat dan menikmati minuman dan snack yang telah disediakan warga dan anggota asrama saling berkomunikasi secara langsung dengan topik yang berbeda-beda. Melalui kegiatan senam terjalin komunikasi yang mendekatkan hubungan anggota AMKT Ruhui Rahayu dan warga. Oleh karena itu asrama mewajibkan seluruh anggota untuk bisa terlibat dalam kegiatan senam sebagaimana jadwal yang telah ditetapkan. Terdapat sanksi berupa teguran atau denda bagi anggota yang melanggar. Hal ini bertujuan agar seluruh anggota asrama dapat bersosialisasi dan menjalin komunikasi yang baik dengan masyarakat.

b. Arisan warga

Arisan merupakan kegiatan eksternal yang diagendakan bersama warga RW 09 Baciro. Arisan dijadwalkan rutin setiap bulannya yang bertepatan setiap pertengahan bulan dengan sistem bergilir ke setiap rumah warga. Saat arisan berlangsung selain mengundi arisan, antara ibu-ibu warga RT 33 Baciro dan anggota asrama saling berkomunikasi.

Proses komunikasi antara anggota asrama dan ibu-ibu warga RW 33 Baciro merupakan komunikasi langsung. Arisan menjadi salah satu waktu yang dimanfaatkan untuk membangun komunikasi secara lebih intensif bersama warga. Proses komunikasi yang dilakukan membahas berbagai topik. Bentuk komunikasi anggota AMKT Ruhui Rahayu dan warga adalah komunikasi dengan memperbicangkan kegiatan maupun informasi yang ada di lingkungan masyarakat RW.09 Baciro.

c. Malam tahun baru warga RW 09 Baciro Perayaan malam tahun baru bersama warga RT09 Baciro merupakan salah satu acara warga RW 09 Baciro yang melibatkan seluruh anggota asrama. Partisipasi anggota asrama saat malam tahun baru tidak hanya sebagai undangan, anggota asrama juga diminta untuk membantu mempersiapkan saat acara sedang berlangsung. Perayaan tahun baru bersama warga RT 33/ RW 09 Baciro diawali dengan sambutan dari tokoh masyarakat, kemudian dilanjutkan dengan makan bersama sambil berbincang - bincang dengan warga dan menikmati hiburan, warga juga 
mempersilahkan anggota asrama yang ingin menyumbangkan penampilan atau pertunjukan.

Perayaan malam tahun baru menjadi sarana bagi anggota asrama untuk berkomunikasi dan belajar langsung terkait hidup bermasyarakat. Proses partisipasi dalam kegiatan malam tahun baru tersebut membangun komunikasi yang lebih dekat dengan masyarakat. Komunikasi yang lebih dekat membuat anggota asrama semakin mudah membaur dengan masyarakat. Hal tersebut terlihat dari anggota asrama yang ikut meramaikan acara, membantu membagikan makanan kepada warga yang sudah berusia lanjut dan membantu bersih-bersih setelah acara.

d. Pemilihan RT/RW

Pemilihan RT dan RW merupakan kegiatan bersama warga yang berdiskusi untuk menentukan ketua RT dan RW. Anggota asrama yang diwakili oleh beberapa orang turut menyaksikan proses tersebut. Kegiatan pemilihan RTdan RW proses komunikasi terjadi secara langsung. Beberapa anggota asrama yang menjadi perwakilan, bertindak sebagai komunikan bersama beberapa warga lainnya untuk mendengarkan berbagai informasi yang disampaikan oleh perwakilan warga sebagai komunikator, berkaitan dengan proses pemilihan ketua RT dan RW. Selain itu, anggota AMKT Ruhui Rahayu aktif menjalin komunikasi dengan warga dengan turut membantu secara teknis agar acara berjalan dengan lancar.

e. Pelantikan Pengurus AMKT Ruhui Rahayu

Pelantikan pengurus AMKT Ruhui Rahayu merupakan salah satu acara ekternal AMKT Ruhui Rahayu yang melibatkan pihak luar seperti asrama dari provinsi lainnya dan masyarakat sekitar asrama khususnya RT dan RW. Saat acara pelantikan pengurus AMKT Ruhui Rahayu warga yang diundang khususnya ketua RT dan RW selalu menghadiri acara tersebut. Kegiatan pelantikan pengurus menjadi salah satu sarana bagi warga untuk mengetahui siapa saja yang menjadi anggota asrama dan pengurus terpilih. Hal ini mempermudah proses komunikasi antara warga dengan anggota asrama. Saat acara pelantikan berlangsung komunikasi antara anggota asrama dengan warga berlangsung dengan saling bertukar informasi. Anggota asrama yang memperkenalkan anggota dan struktur baru kepengurusan asrama kepada warga yang diwakili oleh ketua RT dan RW. Disamping itu dari pihak warga memberikan tanggapan dalam bentuk sambutan yang sampaikan oleh ketua RT dan RW.

f. Kegiatan Insidental.

Peran AMKT Ruhui Rahayu 
dalam proses komunikasi antarbudaya dengan warga, dijalankan dengan mengarahkan anggotanya untuk berpartisipasi tidak hanya pada kegiatan- kegiatan rutin, tetapi pada kegiatan yang bersifat insidental. Kegiatan insidental dalam hal ini adalah kegiatan yang tidak terencana. Seperti ikut serta dalam sosialisasi perpustakaan dan ikut serta ta'ziah saat terdapat lelayu di wilayah setempat. Kehadiran AMKT Ruhui Rahayu dalam kegiatan tersebut menggambarkan pelaksanaan proses komunikasi antarbudaya anggota AMKT Ruhui Rahayu dan warga. Kehadiran Anggota AMKT Ruhui Rahayu mendapat merupakan bentuk penyesuaian dengan lingkungan dan kebiasaan masyarakat setempat, sekaligus menjadi sarana bagi anggota AMKT Ruhui Rahayu memperoleh informasi terkait lingkungan RT 33/ RW 09 Baciro.

\section{Proses Komunikasi Antarbudaya} AMKT Ruhui Rahayu.

Tubbs dan Moss

komunikasi antarbudaya merupakan komunikasi antar orang - orang yang berbeda budaya (baik dalam arti ras, etnik ataupun perbedaan sosial ekonomi) (Sihabudin, 2011:13). Proses komunikasi antarbudaya antara anggota AMKT Ruhui Rahayu dengan warga RT 33/ RW 09 Baciro, merupakan komunikasi antarbudaya yang melibatkan dua pihak yang memiliki latar belakang kebudayaan yang berbeda, yaitu anggota AMKT Ruhui Rahayu yang berasal dari Kalimantan Timur dan warga RT 33 RW 09 Baciro yang berlatar belakang kebudayaan Jawa. Sebagai suatu proses, komunikasi antarbudaya bersifat interaktif (timbal balik), dinamis (secara terus menerus) dan transaksional (melibatkan emosi). Proses komunikasi anggota AMKT Ruhui Rahayu dengan warga berjalan baik komunikasi secara langsung maupun secara tidak langsung.

\section{Komunikasi langsung}

antara anggota AMKT Ruhui Rahayu dengan warga dilakukan melalui tatap muka langsung khususnya melalui berbagai kegiatan atau acara yang langsung mempertemukan warga dan anggota AMKT Ruhui Rahayu. Proses komunikasi antarbudaya anggota AMKT Ruhui Rahayu dengan warga juga dilakukan secara tidak langsung dengan menggunakan media. Sebagaimana penelitian Marselina Lagu (2016) yang menjelaskan bahwa proses komunikasi antarbudaya dilakukan secara langsung maupun dengan media sosial (Facebook, Line, BBM). Salah satu bentuk komunikasi tidak langsung antara anggota AMKT Ruhui Rahayu dan warga dilakukan dengan memberikan undangan untuk menghadiri acara - acara tertentu. Proses komunikasi antarbudaya anggota asrama dan warga melibatkan unsur- unsur sebagai berikut:

a. Komunikator

Komunikator merupakan pihak 
yang mengawali proses komunikasi. Proses komunikasi antarbudaya antara anggota asrama dengan warga RT 33/ RW 09 Baciro kedua belah pihak berperan sebagai komunikator dalam proses komunikasi dalam waktu yang berbeda. Saat bertindak sebagai komunikator anggota asrama memperhatikan penggunaan bahasa yang digunakan dan lebih berhati-hati. Terutama ketika berbicara dengan yang berusia lebih tua dibandingkan anggota asrama. Sebagaimana hasil studi Howard Giles dan Arlene Franklyn Stokes (Liliweri, 2003) bahwa latar belakang demografis seperti umur, jenis kelamin dan sistem politik berpengaruh pada proses komunikasi antarbudaya.

b. Komunikan

Komunikan merupakan pihak yang menerima pesan. Komunikan menjadi tujuan atau sasaran dari komunikator dalam proses komunikasi. Dalam proses komunikasi antarbudaya, baik anggota asrama maupun warga setempat bertindak sebagai komunikan atau penerima pesan secara bergantian. Anggota AMKT Ruhui Rahayu menjadi penerima pesan seperti saat anggota asrama diminta oleh warga untuk ikut dalam kegiatan di masyarakat.

c. Pesan atau Simbolik

Pesan merupakan ide atau gagasan yang dikirim komunikator kepada komunikan. Sedangkan simbol yang digunakan untuk menyampaikan pesan. Bahasa Indonesia menjadi simbol utama yang digunakan dalam proses komunikasi antarbudaya anggota AMKT Ruhui Rahayu dengan warga, karena bahasa Indonesia adalah bahasa yang dipahami bersama. Sebagaimana hasil penelitian Juariyah (2012) dalam penelitiannya tentang "Miskomunikasi Antarbudaya Mahasiswa Pendatang

Kabupaten Jember" bahwa penggunaan bahasa Indonesia menjadikan proses komunikasi antarbudaya menjadi lebih efektif. Teori interaksionisme simbolik juga menjelaskan bahwa proses komunikasi berkaitan dengan penggunaan simbol atau tanda yang dipahami bersama dalam melakukan interaksi. Dalam teori interaksionisme simbolik dijelaskan bahwa pemahaman terhadap simbol diperlukan untuk memahami peran atau makna yang ada dalam pesan yang disampaikan. Sehingga penggunaan Bahasa Indonesia sebagai simbol dalam komunikasi anggota AMKT Ruhui Rahayu dengan warga membuat pesan tersampaikan sebagaimana tujuan dari pesan tersebut dan tidak terdapat perbedaan penafsiran pesan.

d. Media

Media merupakan perantara pesan yang disampaikan. Media yang digunakan dalam proses komunikasi antarbudaya antara anggota asrama dan warga adalah media yang berbentuk undangan untuk menghadiri acara tertentu. Misalkan saat warga 
mengadakan acara tertentu dan turut mengundang anggota asrama. Saat asrama mengadakan acara seperti pelantikan pengurus, AMKT Ruhui Rahayu juga menggunakan undangan sebagai media komunikasi dengan warga untuk menghadiri acara tersebut.

e. Umpan Balik

Proses komunikasi antarbudaya antara anggota asrama dengan masyarakat merupakan komunikasi secara langsung dan tidak langsung. Pada komunikasi langsung umpan balik atau respon langsung diketahui saat proses penyampaian pesan secara langsung.

f. Suasana

Komunikasi antara warga dan anggota asrama berjalan lebih intensif dalam acara atau kegiatan tertentu, baik yang diadakan oleh asrama maupun masyarakat. Pada saat berada dalam satu acara seperti senam rutin, arisan maupun kegiatan lainnya menjadi sarana bagi anggota asrama dan masyarakat untuk berkomunikasi seperti sharing, bertukar informasi dan memberi masukan.

g. Gangguan (Noice/Inference)

Komunikasi antara anggota asrama dengan masyarakat RT 33/ RW 09 Baciro, berjalan dengan baik dan lancar. Adanya perbedaan latar belakang kebudayaan tidak menjadi gangguan dalam proses komunikasi. Penyampaian pesan antara anggota AMKT Ruhui Rahayu dan warga juga tidak terdapat suatu hambatan. Penggunaan bahasa yang dipahami bersama membuat pesan dapat tersampaikan dengan baik. Selain itu durasi waktu saat berkomunikasi dengan warga berpengaruh pada proses komunikasi.

\section{Faktor Pendorong dan}

Penghambat Peran AMKT Ruhui Rahayu dalam Proses Komunikasi Antarbudaya

a. Faktor Pendorong Peran AMKT Ruhui Rahayu dalam Proses Komunikasi Antarbudaya.

1) Faktor Pendorong Intrinsik Peran AMKT Ruhui Rahayu dalam Proses Komunikasi Antarbudaya. Faktor pendorong intrinsik peran AMKT Ruhui Rahayu dalam proses komunikasi antarbudaya berasal dari dalam lingkup asrama yaitu adanya kesadaran untuk membangun komunikasi dengan warga. Sebagaimana menurut Mead dalam Poloma (2004) bahwa dalam Interaksionisme simbolik saat berinteraksi dengan orang lain, seorang individu secara simbolis berinteraksi dengan dirinya sendiri. Kesadaran untuk menjalin komunikasi dengan warga menjadi pendorong bagi asrama dalam menjalankan peran dalam proses komunikasi antarbudaya, sehingga proses 
komunikasi bisa berjalan lebih efektif dan sistematis.

2) Faktor pendorong ekstrinsik peran AMKT Ruhui Rahayu dalam proses komunikasi antarbudaya. Faktor ekstrinsik yang mendorong peran AMKT Ruhui Rahayu dalam proses komunikasi antarbudaya adalah keterbukaan dan sambutan baik warga RT 33/ RW 09 Baciro. Hal tersebut menjadi faktor pendorong pelaksanaan peran AMKT Ruhui Rahayu dalam proses komunikasi antarbudaya dengan warga. Keterbukaan warga membuat anggota asrama lebih mudah beradaptasi dan menjalin komunikasi.

b. Faktor Penghambat Peran AMKT Ruhui Rahayu dalam Proses Komunikasi Antarbudaya.

$\begin{array}{ccc}\text { Pelaksanaan peran } & \text { AMKT } \\ \text { Ruhui Rahayu dalam proses }\end{array}$
komunikasi antarbudaya memiliki faktor yang mengambat berjalannya peran tersebut. Adapun faktor tersebut adalah terkait waktu. Waktu menjadi salah satu penghambat berlangsungnya peran asrama dalam proses komunikasi antarbudaya karena aktivitas atau kesibukan dari masing - masing warga dan anggota AMKT Ruhui Rahayu sebagai mahasiswa yang juga memiliki berbagai aktivitas dan kesibukan di kampus. Keterbatasan waktu membuat komunikasi yang intens lebih banyak berlangsung saat acara atau kegiatan di masyarakat.

\section{Dampak Peran AMKT Ruhui Rahayu} dalam Proses Komunikasi

\section{Antarbudaya}

a. Mempermudah proses pengenalan kebudayaan dan kesenian.

Komunikasi antara anggota asrama dan warga, mempermudah proses pengenalan budaya. Melalui berbagai kegiatan warga mengenal kebudayaan termasuk kesenian dari Kalimantan Timur seperti Tari Dayak. Warga menerima dengan baik kebudayaan termasuk kesenian Kalimantan Timur. Selama proses komunikasi antarbudaya, anggota asrama juga menjadi paham dan memperoleh pengetahuan baru tentang kebudayaan Jawa, seperti kesenian, norma dan tata krama di lingkungan warga RT. 33 RW. 09 Baciro. Sehinga mempermudah beradaptasi.

b. Saling mendukung dalam berbagai kegiatan.

Proses komunikasi antarbudaya yang berlangsung melalui berbagai kegiatan yang melibatkan anggota asrama dan warga, menciptakan hubungan yang saling mendukung antara anggota asrama dan warga. Anggota asrama mendapat dukungan salah satunya pertisipasi dari warga RT. 33 RW 09 Baciro dalam menjalankan kegiatan. 
Warga juga bersedia memberikan bantuan dalam hal lain ketika asrama memerlukan.

Partisipasi anggota asrama dalam kegiatan warga membawa perubahan tersendiri dalam pelaksanaan kegiatan masyarakat. Partisipasi anggota asrama merupakan salah satu bentuk peran baru yang masuk pada struktur masyarakat RT 33/ RW 09 Baciro. Hal tersebut karena anggota asrama merupakan generasi muda yang ada di lingkungan RT 33/ RW 09 Baciro, karena sebagian besar warganya sudah berusia lanjut sedangkan warga setempat yang merupakan generasi muda banyak yang merantau. Hal ini berkaitan dengan perubahan struktur dimasyarakat sebagaimana yang dikemukakan oleh Himes dan Moor (Martono, 2006: 6) bahwa salah satu bentuk perubahan adalah perubahan terkait dimensi struktur yang berkaitan dengan munculnya peran baru di masyarakat.

\section{Simpulan}

Peran AMKT Ruhui Rahayu dalam proses komunikasi antarbudaya dilaksanakan melalui peraturan $3 \mathrm{~s}$ (senyum, sapa, salam), peratuan untuk tertib di lingkungan warga RT. 33 RW 09 Baciro. Disamping itu peran AMKT Ruhui Rahayu dilaksanakan dengan mengarahkan anggotanya untuk turut serta dalam berbagai kegiatan di masyarakat.

Proses komunikasi antarbudaya anggota AMKT Ruhui Rahayu dan warga berlangsung secara langsung dan tidak langsung. Disamping itu komunikasi antarbudaya anggota asrama dan warga berlangsung secara interaktif, dinamis dan transaksional. Unsur yang terlibat dalam komunikasi anggota AMKT dan warga adalah komunikator, komunikan, media, pesan atau simbolik, umpan balik dan suasana. Pelaksanaan peran asrama dalam komunikasi dengan warga terdapat faktor pendorong intrinsik dan ekstrinsik serta faktor penghambat. Pelaksanaan peran AMKT Ruhui Rahayu dalam proses komunikasi antarbudaya membawa dampak positif yaitu mempermudah pengenalan budaya dan saling mendukung dalam berbagai kegiatan.

\section{Ucapan Terima Kasih}

Terima Kasih disampaikan kepada semua pihak yang terlibat dalam penelitian ini sehingga terlaksana dengan baik dan tim redaksi Jurnal Pendidikan Sosiologi Fakultas IImu Sosial UNY yang telah mempublikasikan penelitian ini.

\section{Daftar Pustaka}

Juariyah. 2012. Miskomunikasi Antarbudaya Mahasiswa Pendatang di Kabupaten Jember. Jurnal IImu Komunikasi. Volume 10 (3): $252-260$

Lagu, Marselina. 2016. Komunikasi Antarbudaya di Kalangan Mahasiswa Etnik Papua dan Etnik Manado di Universitas Sam 
Ratulangi Manado. e-journal Acta Diurna.3.

Liliweri, A. 2003. Dasar-dasar Komunikasi Antarbudaya. Yogyakarta: Pustaka Pelajar.

Martono, Nanang. 2016. Sosiologi Perubahan Sosial Perspektif Klasik, Modern,Posmodern dan Poskolonial.Jakarta: Rajawali Pers.

Moleong, Lexy J. 2011. Metodologi Penelitian Kualitatif. Bandung: Remaja Rosdakarya.

Nasdian, Ferdinan T. 2015. Sosiologi Umum. Jakarta: Yayasan Obor Indonesia.

Ngalimun. 2018. Komunikasi Antarbudaya. Yogyakarta: Pustaka Pelajar.

Purwaningsih, Ernawati.2014. Interaksi Penghuni Asrama Dengan Masyarakat Sekitar Suatu Pijakan Awal Multikulturalisme Kasus Lima Asrama Daerah Istimewa Yogyakarta. Yogyakarta: Balai Pelestarian Nilai Budaya (BPNB). Tersedia pada https://ia601304.us.archive.org/11/it ems/PenelitianInteraksi/Buku\%205 $\% 20$ Penelitian\%20Interaksi.pdf.

(Diakses 20 Desember 2018)

Poloma, Margaret M. 2004. Sosiologi Kontemporer. Jakarta: Raja Grafindo Persada.

Ritzer, George. 1992.Sosiologi: IImu Pengetahuan Berparadigma Ganda. Jakarta: Rajawali.

Ritzer, George. 2014. Teori Sosiologi Modern Edisi Ketujuh. Jakarta: Kencana.

Saefullah, Ujang. 2007. Kapita Selekta Komunikasi Pendekatan Budaya dan Agama. Bandung: Simbiosa Rekatama Media.

Scott, John.2011. Sosiologi The Key Concepts.Jakarta: Rajawali Pers.

Sugiyono. 2017. Metode Penelitian Pendidikan Pendekatan Kuantitatif, Kualitatif dan R\&D. Bandung: Alfabeta.

Sihabudin, Ahmad. 2011. Komunikasi Antarbudaya Suatu Perspektif Multidimensi. Jakarta: Bumiaksara.

Susanto, Tri Agus. Siswowiharjo. 2016. Peran Asrama Mahasiswa di Yogyakarta. Tersedia di http://www.indeksberita.com/peran- asrama-mahasiswa-yogyakarta/ . Diakses 16 Desember 2018.

Umiarso dan Elbadiansyah. 2014. Interaksionisme Simbolik dari Era Klasik Hingga Modern. Jakarta Rajawali Pers. 